\title{
MODEL EMPIRIS ONLINE TRUST DAN REPEAT PURCHASE PELANGGAN TERHADAP SITUS E-COMMERCE
}

\author{
Roswita Hafni \\ roswitahafni2019@gmail.com \\ Jasman Saripuddin Hasibuan \\ Muslih \\ Willy Yusnandar \\ Fakultas Ekonomi dan Bisnis, Universitas Muhammadiyah Sumatera Utara
}

\begin{abstract}
This study aims to determine and analyze the empirical online trust model and repeat purchase of customers on ECommerce Sites (Case Study of E-Commerce Customers in Medan). This study used an explanatory research approach. The scale of variables measurement used the Ordinal Scale with the technique of variables measuring by using a Likert scale. The population in this study is the Medan community. The sampling method is done by purposive sampling (judgmental) and snowball sampling methods. The sample selection criteria in this study are Medan people who have visited and conducted transactions in e-commerce in Indonesia more than 3 times. Data collection techniques used were interviews, questionnaires and literature study. The data analysis method used is the Structural Equation Model. The results showed that Web Quality, Perceived Risk, and Online Trust significantly influence Repeat Purchase, as well as Web Quality and Perceived Risk significantly influence online trust. Web Quality influences Repeat Purchase through the Online Trust variable, and Perceived Risk influences Repeat Purchase through the Online Trust variable.
\end{abstract}

Key words: online trust; repeat purchases; customers; e-commerce.

\begin{abstract}
ABSTRAK
Penelitian ini bertujuan untuk mengetahui dan menganalisis model empiris online trust dan repeat purchase pelanggan Terhadap Situs E-Commerce (Studi Kasus pada Pelanggan E-Commerce di Kota Medan). Penelitian ini menggunakan pendekatan penelitian eksplanatori. Skala pengukuran variabel menggunakan Skala Ordinal dengan teknik pengukuran variabel menggunakan skala Likert. Populasi dalam penelitian ini adalah masyarakat kota Medan. Metode pengambilan sampel dilakukan dengan metode Purposive sampling (judgmental) dan snowball sampling. Kriteria pemilihan sampel dalam penelitian ini adalah masyarakat kota Medan yang pernah berkunjung dan melakukan transaksi di ecommerce yang ada di Indonesia lebih dari 3 kali. Teknik pengumpulan data yang digunakan yaitu wawancara, kuesioner (angket) dan studi pustaka. Metode analisis data yang digunakan adalah Model Persamaan Struktural (Structural Equation Model). Hasil penelitian menunjukkan bahwa Web Quality, Perceived Risk, dan Online Trust berpengaruh signifikan terhadap Repeat Purchase, begitu juga Web Quality dan Perceived Risk berpengaruh signifikan terhadap online trust. Web Quality berpengaruh terhadap Repeat Puchase melalui variabel Online Trust, dan Perceived Risk berpengaruh terhadap Repeat Purchase melalui variabel Online Trust.
\end{abstract}

Kata kunci: online trust; repeat purchase; pelanggan; e-commerce.

\section{PENDAHULUAN}

Pada zaman sekarang ini, teknologi memegang peranan penting dalam kehidupan dan berdampak langsung kepada perubahan kinerja manusia. Salah satu produk inovasi teknologi yang paling populer saat ini adalah teknologi internet (Fitdiarini, 2015). Perkembangan pesat 
internet di Indonesia menjadikan Indonesia menjadi lahan bisnis online yang menjanjikan. Saat ini, salah satu fenomena e-commerce yang berkembang pesat adalah banyak munculnya situs jual beli online. Banyak kemudahan yang didapatkan dalam transaksi secara online, akan tetapi masyarakat Indonesia mayoritas masih lebih suka untuk berbelanja secara konvensional, yang masih menjadi pertimbangan konsumen yaitu tingkat kepercayaan yang mereka tunjukan pada situs jual-beli tersebut (Putra et al., 2017).

Perkembangan Internet dan Dunia Wide Web saat ini telah meningkat sangat pesat, terutama untuk transaksi elektronik (Salo dan Karjaluoto, 2007). Pengembangan Internet telah sangat memengaruhi lingkungan pemasaran di seluruh dunia dan Internet telah memberikan perusahaan dengan kemampuan untuk memperluas jangkauan bisnis mereka melalui e-commerce (Alkailani dan Kumar, 2011). Tidak ada keraguan pangsa pasar e-commerce mengalami pertumbuhan yang cepat di Indonesia. Jumlah pengguna Internet di Indonesia adalah sekitar 30\% dari total populasi Indonesia, yang mengubah pasar e-commerce menjadi tambang emas yang sangat menggoda bagi orang-orang yang bisa melihat potensi di masa depan (Mahatma, 2016).

Kualitas situs web memiliki peran penting dalam mengembangkan niat beli. Situs web yang luar biasa kualitas akan meningkatkan niat beli pelanggan (Ali, 2016). Niat pembelian online adalah kemauan dan keinginan pelanggan untuk berpartisipasi dalam transaksi online, termasuk proses evaluasi informasi kualitas dan produk situs web (Wang et al., 2015). Niat pembelian online adalah keinginan konsumen untuk membeli produk atau layanan dalam situs spesifik (Youl dan Swinder, 2014). Nilashi et al., (2016) menyatakan bahwa atribut situs kualitas web dapat mempengaruhi kepercayaan konsumen terhadap agen. Niat pembelian dipengaruhi oleh kepercayaan dan perspektif konsumen menuju kegunaan situs website.
(Doney et al., 1998); (Eden, 1988); (Kim et al., 2007) menyatakan bahwa kepercayaan adalah faktor yang sangat berpengaruh dalam menjelaskan proses online shopping. Fitur utama dari hubungan antara pembeli dan penjual adalah kepercayaan (Lien et al., 2015). Kepercayaan paling penting dalam suatu hubungan adalah kepercayaan hubungan antara manusia dan mesin atau sistem online (Salo dan Karjaluoto, 2007). Komponen kepercayaan adalah keyakinan juga harapan dan kemauan untuk menerima risiko (Chek dan Ho, 2016). Kepercayaan merupakan hal yang sangat penting dalam sebuah lingkungan online, khususnya dalam pembayaran dan privasi (Salo dan Karjaluoto, 2007). Kepercayaan adalah pusat perilaku manusia, yang disebut disangkal. Selain itu, realisasi ini berjalan jauh di dalam jiwa manusia (Sharma, 2013). Kepercayaan adalah alat rekomendasi yang dapat membantu konsumen dalam membuat keputusan yang lebih baik (Nilashi et al., 2016). Jadi, membangun kepercayaan adalah kunci yang sangat penting dalam e-commerce (Yousafzai et al., 2003). Fitur utama dari hubungan antara pembeli dan penjual adalah kepercayaan (Lien et al., 2015).

Dalam pemasaran banyak peneliti telah menyoroti pentingnya pembelian berulang (repeat purchase). Semua penjual tertarik dalam mengetahui bagaimana konsumen membuat keputusan pembelian mereka dan apa yang memotivasi mereka untuk membeli kembali. Pembelian ulang adalah sumber utama pendapatan dan pembangunan hubungan jangka panjang untuk bisnis ritel (Gupta dan Kim, 2007). Hal ini tidak hanya membawa pendapatan bagi perusahaan tetapi juga menggambarkan hubungan positif dari sisi konsumen yang kemudian dapat menghasilkan positif word of mouth dan pelanggan setia untuk perusahaan. Transaksi online perusahaan harus mampu mengikat pelanggan kedalam bentuk hubungan yang kuat (Chairunnisa dan Priyono, 2018). Hal ini bertujuan agar pelanggan melakukan pembelian berulang. Tetapi mempertahankan online pelanggan 
lebih rumit dan menantang bagi penjual karena kurangnya interaksi tatap muka. Dan itu menjadi sulit untuk menilai kepercayaan dari penjual (Pavlou et al., 2007). Pembelian kembali telah didefinisikan oleh Chou dan Hsu (2015) sebagai penggunaan kembali saluran online pelanggan untuk membeli dari pengecer tertentu. Telah dikonfirmasi berkali-kali bahwa pelanggan yang berulang membawa lebih banyak keuntungan ke perusahaan karena pelanggan yang berpengalaman lebih murah untuk mempertahankan dan karena mereka sudah akrab dengan pembelian online proses, mereka menghabiskan lebih sedikit waktu dalam mengevaluasi dan melakukan pembelian (Chiu et al., 2014). Ndubisi dan Moi (2005) menyatakan bahwa pembelian ulang (repeat purchase) tergantung pada tingkat ketahanan suatu produk. Niat pembelian berulang terjadi ketika konsumen memulai upaya untuk membeli merek, produk, atau layanan yang sama lagi. Ini berfungsi sebagai pendahulu atau prediktor untuk aktual perilaku pembelian (Jones dan Sasser, 1995); ( Lin dan Liang, 2011); (Kuo et al., 2013). Berdasarkan paparan tersebut di atas, faktorfaktor yang pembelian ulang konsumen diantaranya adalah kepercayaan pelanggan (trust), kepercayaan konsumen dipengaruhi oleh faktor risiko dalam transaksi (perceived risk) (Putra et al., 2017) dan faktor kualitas web (web quality) (Putra et al., 2017); (Purbasari, 2017) dan (Siagian dan Cahyono, 2014).

Di bidang e-commerce, menurut Pavlou (2003) kepercayaan adalah keyakinan yang membuat konsumen rentan terhadap kebaikan penjual online setelah mempelajari karakteristik mereka. Pavlou dan Gefen (2004), memahami kepercayaan sebagai kepercayaan umum di penjual online yang menghasilkan niat perilaku. Kim et al., (2008) mendefinisikan kepercayaan sebagai keyakinan subyektif yang akan dilakukan penjual online dalam memenuhi kewajiban transaksionalnya, karena kewajiban tersebut dipahami oleh konsumen. Moorman et al., (1993) mengartikan kepercayaan sebagai kemauan seorang individu untuk bergantung pada pihak lain yang terlibat dalam pertukaran. Kepercayaan adalah faktor sentral yang memungkinkan perdagangan online (Weisberg et al., 2011). Kepercayaan diukur dalam dua dimensi, yaitu, kompetensi dan kebijakan kompetensi, yang dapat mengarah pada kepercayaan merek (Li et al., 2008). Kepercayaan diakui sebagai faktor yang mempengaruhi kuat niat perilaku offline dan online, tetapi di Web itu sangat penting dan sangat penting ditekankan (Harris dan Goode, 2010). Niat pembelian kembali menilai niat konsumen untuk tetap dengan penyedia online saat ini. Kepercayaan adalah sangat penting karena hal ini merupakan salah satu metode yang paling efektif untuk mengurangi ketidakpastian konsumen, karena situs website itu sendiri adalah satu-satunya sumber informasi untuk diatasi ketidakpastian (Weisberg et al., 2011). Jones dan Leonard (2008) menemukan konstruk kepercayaan itu mempengaruhi ketakutan konsumen akan ketidakpercayaan dan risiko dicurangi. Kepercayaan konsumen akan mengurangi persepsi risiko dan meningkatkan niat pembelian (Pavlou dan Gefen, 2004), sebaliknya risiko yang rendah akan meningkatkan niat untuk membeli (Chong et al., 2003).

Kim dan Lennon (2013) mengartikan persepsi risiko sebagai keyakinan konsumen tentang potensi hasil yang tidak pasti dari pembelian online. Schiffman dan Wisenblit (2015) menyatakan perceived risk sebagai ketidakpastian yang dihadapi konsumen ketika mereka tidak dapat melihat konsekuensi dari keputusan pembelian mereka. Kemudian Zheng et al., (2012) menyatakan Risiko yang dirasakan adalah ukuran ketidakpuasan yang mungkin atau yang diharapkan dengan keputusan pembelian, berdasarkan tujuan pembelian pembeli. Samadi dan Yaghoob-Nejadi (2009) menyatakan Risiko yang dirasakan berarti keyakinan subyektif individu tentang kemungkinan konsekuensi negatif dari keputusannya. Risiko yang dirasakan dianggap konsep dasar perilaku konsumen 
dan sering digunakan untuk menjelaskan kedua persepsi risiko dan metode pengurangan risiko yang digunakan oleh konsumen (McOmish dan Quester, 2005). Risiko yang dirasakan didefinisikan sebagai sejauh mana seseorang mengekspresikan ketidakpastian tentang suatu layanan atau barang (Dai et al., 2014). Sektor jasa dicirikan oleh tingkat pengalaman dan kepercayaan yang lebih tinggi atribut dan level rendah dari atribut pencarian. Intangibilitas, heterogenitas dan ketidakterpisahan, sebagai karakteristik unik dari layanan, semua berkontribusi pada tingkat pengalaman yang lebih tinggi, di mana tinggi tingkat ketidakpastian bagi konsumen hadir. Perdagangan online, karena sifatnya yang tidak kasat mata sebagai jenis layanan yang unik, membawa bentuk risiko tambahan. Oleh karena itu, risiko itu diakui Persepsi secara langsung mempengaruhi pembelian dan niat pembelian: ketika konsumen dipersepsikan risiko tinggi, kemungkinan konsumen untuk membeli atau membeli kembali secara online akan rendah. Di dalam cara, risiko yang dirasakan mempengaruhi sikap pembelian online (Lobb et al., 2007), dan memiliki dampak negatif pada sikap pembeli terhadap belanja online ( $\mathrm{O}^{\prime}$ Cass dan Fenech, 2003); (Heijden et al., 2003) dan tentang perilaku pembelian konsumen (Kovacs et al., 2011). Oleh karena itu, perlu tidak hanya untuk terus memantau dampak negatif dari risiko yang dirasakan pada sikap dan perilaku belanja online konsumen, tetapi juga secara proaktif mengelola dan mengurangi risiko yang dirasakan untuk meningkatkan niat pembelian kembali. Banyak penelitian belum secara sistematis mengeksplorasi bagaimana kepercayaan dan risiko yang dirasakan dapat beroperasi dalam kombinasi untuk mempengaruhi keputusan tersebut (Kim et al., 2008). Dengan demikian, konsumen akan cenderung memilih online shop yang dipercaya untuk mengurangi risiko (Hong, 2015). Kualitas situs web adalah faktor kunci dalam perdagangan elektronik karena persepsi pelanggan terhadap kualitas situs web berdampak positif pada niat mereka untuk menggunakan situs (Chang dan Chen, 2008) dan secara langsung mempengaruhi niat pembelian (McKnight et al., 2002). Kualitas situs web adalah kualitas yang dirasakan secara keseluruhan dari suatu Situs web menurut sudut pandang pelanggan (Yoo dan Donthu, 2001). Aladwani dan Palvia (2002) telah mendefinisikan persepsi kualitas Situs Web sebagai evaluasi pelanggan tentang fitur-fitur dalam situs web yang memenuhi kebutuhan mereka dan sangat memengaruhi seluruh keunggulan situs web tersebut. Ada banyak dimensi kualitas situs web: keamanan, kualitas konten, kualitas informasi, kemudahan penggunaan, dan kualitas layanan, penampilan, nilai hiburan (Yoo dan Donthu, 2001); (Aladwani dan Palvia, 2002); (Loiacono et al., 2002); (Wolfinbarger dan Gilly, 2003). Liu dan Arnett (2000) mengeksplorasi faktorfaktor yang mempengaruhi keberhasilan situs web. Hasil mengungkapkan bahwa keberhasilan situs Web dalam konteks ecommerce terkait dengan empat faktor utama: kualitas informasi dan layanan, penggunaan sistem, main-main, dan kualitas desain sistem.

\section{TINJAUAN TEORETIS}

Kualitas situs web adalah platform Teknologi Informasi (Liu dan Arnett, 2000) yang mencapai efektivitas situs web (Lin, 2008). Ini memberikan proses pembelian dan pengiriman produk dan layanan yang efektif dan efisien kepada pelanggan (Zeithaml et al., 2002). Akibatnya, dengan kualitas situs web yang baik, ia memperoleh kepercayaan pelanggan, kepercayaan pada e-store tertentu, dan meningkatkan penjualan. Untuk tujuan penelitian ini, kualitas situs web terdiri dari desain situs web, konten situs web, dan struktur situs web. Aladwani dan Palvia (2002) telah mengidentifikasi persepsi pelanggan terhadap kualitas situs web sebagai evaluasi pengguna tentang fiturfitur dalam situs web yang memenuhi kebutuhan mereka dan mengesankan keunggulan total situs web tersebut. Ada banyak dimensi kualitas situs web yang 
diklarifikasi oleh para peneliti sebelumnya dan dapat diurutkan ke dalam beberapa kategori seperti keamanan, kesenangan, kualitas informasi, kemudahan penggunaan, dan kualitas layanan (Yoo dan Donthu, 2001); (Aladwani dan Palvia, 2002); (Wolfinbarger dan Gilly, 2003). Kualitas situs web adalah kualitas yang dirasakan secara keseluruhan dari suatu situs web menurut sudut pandang pelanggan (Yoo dan Donthu, 2001). (Bai et al., 2008) menemukan bahwa kualitas web berdampak pada niat pembelian. (Sin et al., 2012) menunjukkan bahwa 3 faktor kemudahan penggunaan, norma subyektif dan manfaat yang dirasakan memiliki dampak positif pada niat beli

$\mathrm{H}_{1}$ : Web quality berpengaruh terhadap online trust

$\mathrm{H}_{2}$ : Web Quality berpengaruh terhadap Repeat Puchase

Persepsi secara langsung mempengaruhi pembelian dan niat pembelian: ketika konsumen dipersepsikan risiko tinggi, kemungkinan konsumen untuk membeli atau membeli kembali secara online akan rendah. Di dalam cara, risiko yang dirasakan mempengaruhi sikap pembelian online (Lobb et al., 2007), dan memiliki dampak negatif pada sikap pembeli terhadap belanja online (O'Cass dan Fenech, 2003); (Heijden et al., 2003) dan tentang perilaku pembelian konsumen (Kovacs et al., 2011). Oleh karena itu, perlu tidak hanya untuk terus memantau dampak negatif dari risiko yang dirasakan pada sikap dan perilaku belanja online konsumen, tetapi juga secara proaktif mengelola dan mengurangi risiko yang dirasakan untuk meningkatkan niat pembelian kembali. Banyak penelitian belum secara sistematis mengeksplorasi bagaimana kepercayaan dan risiko yang dirasakan dapat beroperasi dalam kombinasi untuk mempengaruhi keputusan tersebut (Kim et al., 2008). Dengan demikian, konsumen akan cenderung memilih online shop yang dipercaya untuk mengurangi risiko (Hong, 2015). Dengan demikian, dirumuskan hipotesis penelitian yaitu
$\mathrm{H}_{3}$ : Perceived Risk berpengaruh terhadap Online Trust

$\mathrm{H}_{4}$ : Perceived Risk berpengaruh terhadap Repeat Puchase

Kepercayaan diakui sebagai faktor yang mempengaruhi kuat niat perilaku offline dan online, tetapi di Web itu sangat penting dan sangat penting ditekankan (Harris dan Goode, 2010). Niat pembelian kembali menilai niat konsumen untuk tetap dengan penyedia online saat ini. Kepercayaan adalah sangat penting karena merupakan salah satu metode yang paling efektif untuk mengurangi ketidakpastian konsumen, karena situs web itu sendiri adalah satusatunya sumber informasi untuk diatasi ketidakpastian (Weisberg et al., 2011). Jones dan Leonard (2008) menemukan konstruk kepercayaan itu mempengaruhi ketakutan konsumen akan ketidakpercayaan dan risiko dicurangi. Kepercayaan konsumen akan mengurangi persepsi risiko dan meningkatkan niat pembelian (Pavlou dan Gefen, 2004), sebaliknya risiko yang rendah akan meningkatkan niat untuk membeli (Chong et al., 2003). Pentingnya kepercayaan online, sebagian, didorong oleh temuan empiris yang ditemukan hubungan antara kepercayaan konsumen dan niat beli mereka (Harris dan Goode, 2010), di mana niat pembelian kembali adalah penentu utama tindakan pembelian. Kepercayaan menjadi penting karena ada risiko (McKnight et al., 2002). Berdasarkan teori dan penjelasan sebelumnya, maka hipotesis penelitian adalah:

$\mathrm{H}_{5}$ : Online Trust berpengaruh terhadap Repeat Puchase

\section{METODE PENELITIAN}

Penelitian ini menggunakan pendekatan penelitian eksplanatori, yang bertujuan untuk menjelaskan hubungan sebab akibat antara variabel penelitian dan hipotesis pengujian (Nasution et al., 2020). Skala pengukuran variabel menggunakan Skala Ordinal dengan teknik pengukuran variabel menggunakan skala Likert yaitu metode pengukuran sikap (Umar, 2000). Populasi 
penelitian ini adalah masyarakat kota Medan. Pengambilan sampel dilakukan dengan metode Purposive sampling (judgmental) dan snowball sampling. Kriteria pemilihan sampel dalam penelitian ini adalah masyarakat kota Medan yang pernah berkunjung dan melakukan transaksi di $e^{-}$ commerce yang ada di Indonesia lebih dari 3 kali.

Untuk menentukan ukuran sampel mengacu pada pendapat (Ghozali, 2008) yang menyatakan bahwa jumlah sampel dapat dihitung dari jumlah indikator dikalikan dengan 5 -10. Karena penelitian ini menggunakan 5 variabel konstruk yang jumlah indikator keseluruhannya sebesar 31, sehingga sampel yang dibutuhkan dalam studi ini minimal sebanyak $31 \times 5=155$ orang. Jenis data yang akan digunakan adalah data subyek (selfreport data), sedangkan sumber data adalah sumber data primer. Teknik pengumpulan data dengan wawancara, kuesioner (angket) dan studi pustaka.

Metode analisis data yang digunakan adalah Model Persamaan Struktural dari paket software statistik LISREL 8.80.

\section{ANALISIS DAN PEMBAHASAN}

Analisis Validitas Model Pengukuran.

Berdasarkan hasil output LISREL 8.80 pada gambar 1, dapat dilihat bahwa persamaan pengukuran untuk koefisien Eksogen masing-masing indikator memiliki $t$ value $\geq 1.96$ yang berarti bahwa indikatorindikator Eksogen semuanya valid dan signifikan secara statistik dengan tingkat signifikansi sebesar $5 \%$.

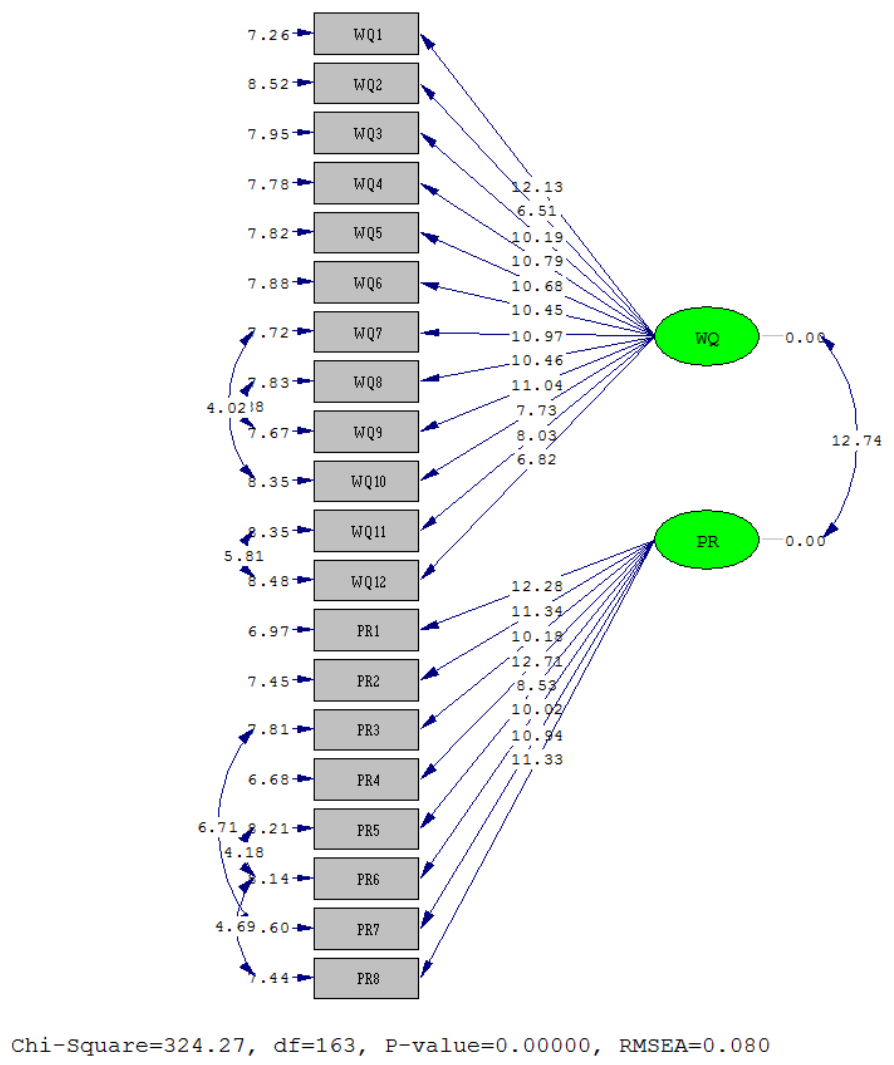

Gambar 1

Sumber: Output LISREL 8.80

Path Variabel Eksogen (t-value)

Berdasarkan gambar 1 di atas dapat dilihat bahwa persamaan pengukuran untuk koefisien Eksogen masing-masing indikator memiliki $t$-value $\geq 1,96$ yang berarti bahwa indikator-indikator Eksogen semuanya valid dan signifikan. 
Tabel 1

Realibilitas Variabel Eksogen

\begin{tabular}{|c|c|c|c|c|c|c|c|c|}
\hline \multirow{2}{*}{ Indikator } & \multirow{2}{*}{ SLF } & \multirow{2}{*}{ Error } & \multicolumn{6}{|c|}{ Construct Reliability } \\
\hline & & & $\sum S L F$ & $\left(\sum \mathrm{SLF}\right)^{2}$ & $\sum \mathrm{SLF}^{2}$ & Eerror & Nilai CR & Nilai VE \\
\hline \multicolumn{9}{|c|}{ Web Quality } \\
\hline WQ1 & 0.82 & 0.328 & \multirow{12}{*}{8.320} & \multirow{12}{*}{69.222} & \multirow{12}{*}{5.888} & \multirow{12}{*}{6.112} & \multirow{12}{*}{0.919} & \multirow{12}{*}{0.491} \\
\hline WQ2 & 0.51 & 0.740 & & & & & & \\
\hline WQ3 & 0.73 & 0.467 & & & & & & \\
\hline WQ4 & 0.76 & 0.422 & & & & & & \\
\hline WQ5 & 0.75 & 0.438 & & & & & & \\
\hline WQ6 & 0.74 & 0.452 & & & & & & \\
\hline WQ7 & 0.77 & 0.407 & & & & & & \\
\hline WQ8 & 0.74 & 0.452 & & & & & & \\
\hline WQ9 & 0.77 & 0.407 & & & & & & \\
\hline WQ10 & 0.59 & 0.652 & & & & & & \\
\hline WQ11 & 0.61 & 0.628 & & & & & & \\
\hline WQ12 & 0.53 & 0.719 & & & & & & \\
\hline \multicolumn{9}{|c|}{ Perceived Risk } \\
\hline PR1 & 0.83 & 0.311 & \multirow{8}{*}{6.110} & \multirow{8}{*}{37.332} & \multirow{8}{*}{4.698} & \multirow{8}{*}{3.302} & \multirow{8}{*}{0.919} & \multirow{8}{*}{0.587} \\
\hline PR2 & 0.79 & 0.376 & & & & & & \\
\hline PR3 & 0.73 & 0.467 & & & & & & \\
\hline PR4 & 0.85 & 0.278 & & & & & & \\
\hline PR5 & 0.64 & 0.590 & & & & & & \\
\hline PR6 & 0.72 & 0.482 & & & & & & \\
\hline PR7 & 0.77 & 0.407 & & & & & & \\
\hline PR8 & 0.78 & 0.392 & & & & & & \\
\hline
\end{tabular}

Sumber: Output LISREL 8.80

Dari perhitungan pada Tabel 1 diatas, terlihat bahwa nilai dari construct reliability secara keseluruhan pada Eksogen adalah diatas 0.70, sedangkan varians extracted merupakan opsional dalam menentukan tingkat reliabilitas laten variable masingmasing melebihi $40 \%$ pada variable Eksogen. Hal ini menunjukkan bahwa reliabilitas model pengukuran ini konstruk Eksogen (Web Quality dan Perceived Risk) didukung oleh data yang diperoleh.

Berdasarkan gambar 2 dapat dilihat bahwa persamaan pengukuran untuk koefisien Endogen masing-masing indikator memiliki $t$-value $\geq 1,96$ yang berarti bahwa indikator-indikator Endogen semuanya valid dan signifikan.

Dari Tabel 2, dapat dilihat bahwa nilai dari construct reliability secara keseluruhan pada Endogen adalah lebih dari 0,70. sedangkan varians extracted merupakan opsional dalam menentukan tingkat reliabilitas laten variable masing-masing lebih dari $40 \%$ pada variable Endogen. Hal ini menunjukkan bahwa reliabilitas model pengukuran ini konstruk Endogen didukung oleh data yang diperoleh.

\section{Analisis Model Struktural}

Setelah melakukan perhitungan dan analisis terhadap Confirmatory Factor Analysis (CFA), maka dapat diukur latent score variabel (LVS) untuk masing-masing dimensi guna direduksi menjadi indikator pada setiap variabel.

Pada Tabel 3, kita bisa melihat nilai $\chi^{2} /$ df sebesar 1,736 yang masuk ke dalam kategori good fit karena masih dibawah 5 . Nilai RMSEA, NFI, dan RFI NNFI, IFI, dan CFI semuanya masuk ke dalam kategori good fit. Jadi dapat disimpulkan bahwa kecocokan keseluruhan model sudah sangat baik. 


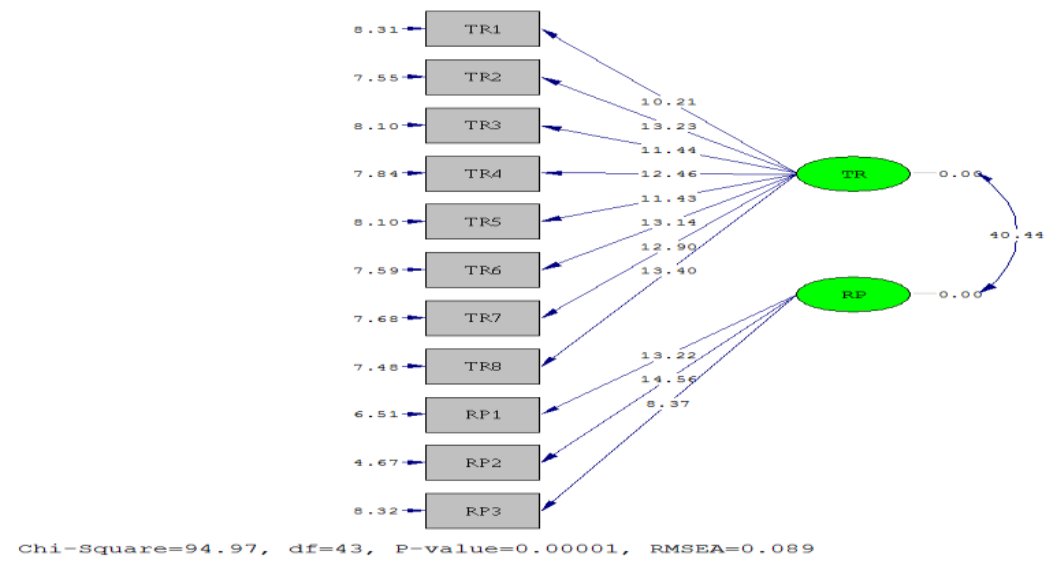

Gambar 2

Path Variabel Endogen (t-value)

Sumber: Output LISREL 8.80

Tabel 2

Realibilitas Variabel Endogen

\begin{tabular}{|c|c|c|c|c|c|c|c|c|}
\hline \multirow{2}{*}{ Indikator } & \multirow{2}{*}{ SLF } & \multirow{2}{*}{ Error } & \multicolumn{6}{|c|}{ Construct Reliability } \\
\hline & & & $\sum S L F$ & $\left(\sum \text { SLF }\right)^{2}$ & $\sum$ SLF $^{2}$ & Eerror & Nilai CR & Nilai VE \\
\hline \multicolumn{9}{|l|}{ Trust } \\
\hline TR1 & 0.72 & 0.482 & \multirow{8}{*}{6.520} & \multirow{8}{*}{42.510} & \multirow{8}{*}{5.331} & \multirow{8}{*}{2.669} & \multirow{8}{*}{0.941} & \multirow{8}{*}{0.666} \\
\hline TR2 & 0.86 & 0.260 & & & & & & \\
\hline TR3 & 0.78 & 0.392 & & & & & & \\
\hline TR4 & 0.83 & 0.311 & & & & & & \\
\hline TR5 & 0.78 & 0.392 & & & & & & \\
\hline TR6 & 0.85 & 0.278 & & & & & & \\
\hline TR7 & 0.84 & 0.294 & & & & & & \\
\hline TR8 & 0.86 & 0.260 & & & & & & \\
\hline \multicolumn{9}{|c|}{ Repeated Purchase } \\
\hline RP1 & 0.87 & 0.243 & \multirow{3}{*}{2.410} & \multirow{3}{*}{5.808} & \multirow{3}{*}{1.988} & \multirow{3}{*}{1.012} & \multirow{3}{*}{0.852} & \multirow{3}{*}{0.663} \\
\hline RP2 & 0.92 & 0.154 & & & & & & \\
\hline RP3 & 0.62 & 0.616 & & & & & & \\
\hline
\end{tabular}

Sumber: Output LISREL 8.80

Tabel 3

Goodness of Fit Structural Equation Model

\begin{tabular}{lcc}
\hline \multicolumn{1}{c}{ Ukuran GoF } & Nilai & Tingkat Kecocokan \\
\hline \multicolumn{1}{c}{$\chi^{2} / \mathrm{df}$} & 1.736 & GoodFit \\
Root Mean Square Error of & 0.069 & Good Fit \\
Approximation (RMSEA) & & \\
Non-Normed Fit Index (NNFI) & 0,97 & Good Fit \\
Normed Fit Index (NFI) & 0.96 & Good Fit \\
Relative Fit Index (RFI) & 0.95 & Good Fit \\
Incremental Fit Index (IFI) & 0,98 & Good Fit \\
Comparative Fit Index (CFI) & 0,98 & Good Fit \\
\hline Sumber: Output Lis
\end{tabular}




\section{Analisis Hubungan Kausal}

Analisis hubungan kausal dilakukan dengan menggunakan tingkat signifikansi $5 \%$, sehingga nilai $t$-value adalah \pm 1.96 .
Hasil estimasi semua hubungan kausal penelitian seperti terlihat Gambar 3 berikut ini:

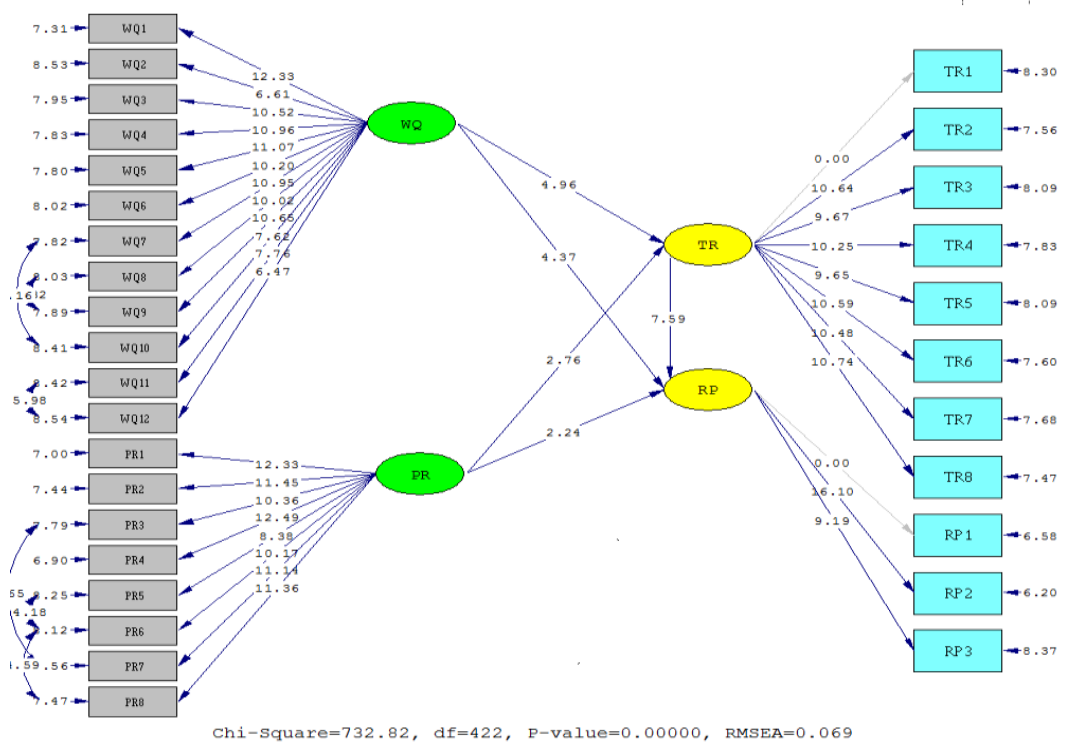

Gambar 3

Model Struktural (t-values)

Sumber: Output LISREL 8.80

Dari Gambar 3 di atas, terlihat bahwa terdapat 5 koefisien lintasan yang signifikan dan tidak ada koefisien lintasan yang tidak signifikan.

\section{Pengujian Hipotesis}

Dalam penelitian ini, terdapat 5 (lima) hipotesis dan diuji dengan tingkat signi- fikansi 5\%, yang diharapkan akan menghasilkan critical t-value sebesar $\pm 1,96$. Hipotesis akan didukung jika $t$-value $\geq 1,96$, sedangkan hipotesis tidak didukung jika $\mathrm{t}$ value $<1,96$.

Hasil pengujian hipotesis, dilihat pada Tabel 4 dibawah ini:

Tabel 4

Pengujian Hipotesis Langsung

\begin{tabular}{|c|c|c|c|c|}
\hline Hipotesis & Pernyataan & T-Hitung & T-Tabel & Keterangan \\
\hline $\mathrm{H}_{1}$ & $\begin{array}{l}\text { Web Quality berpengaruh } \\
\text { terhadap Online Trust }\end{array}$ & 4.96 & \multirow{5}{*}{1,96} & Significant \\
\hline $\mathrm{H}_{2}$ & $\begin{array}{l}\text { Web Quality berpengaruh } \\
\text { terhadap Repeat Puchase }\end{array}$ & 4.37 & & Significant \\
\hline $\mathrm{H}_{3}$ & $\begin{array}{l}\text { Perceived Risk berpengaruh } \\
\text { terhadap Online Trust }\end{array}$ & 2.76 & & Significant \\
\hline $\mathrm{H}_{4}$ & $\begin{array}{l}\text { Perceived Risk berpengaruh } \\
\text { terhadap Repeat Puchase }\end{array}$ & 2.24 & & Significant \\
\hline $\mathrm{H}_{5}$ & $\begin{array}{l}\text { Online Trust berpengaruh } \\
\text { terhadap Repeat Puchase }\end{array}$ & 7.59 & & Significant \\
\hline
\end{tabular}


Tabel 5

Pengujian Hipotesis Model Penelitian Tidak Langsung

\begin{tabular}{cc}
\hline Hipotesis & Intervening \\
\hline Pengaruh Variabel Tidak Langsung (thitung) & Online Trust \\
Web Quality berpengaruh terhadap Repeat Puchase & 4.56 \\
Perceived Risk berpengaruh terhadap Repeat Puchase & 4.47 \\
\hline Sumber: Output LISREL 8.80
\end{tabular}

Berdasarkan hasil perhitungan seperti yang terlihat pada Tabel 4, diperoleh hasil $t$ value sebesar $4,96>1,96$, sehingga disimpulkan bahwa variabel Web Quality berpengaruh positif terhadap online trust secara signifikan. Hal ini berarti bahwa semakin baik Web Quality yang dirasakan responden, maka online trust akan semakin baik pula. Hasil temuan ini menjelaskan bahwa ketika konsumen menilai baik terhadap kualitas website menyebabkan semakin tingginya kepercayaan konsumen. Hasil ini didukung oleh hasil penelitian dari (Wang et al., 2015) menemukan bahwa kualitas web memiliki efek positif dan signifikan terhadap trust. Fitur situs web dirancang untuk memenuhi kebutuhan pengguna dan mencerminkan keunggulan seluruh situs. Kualitas situs web yang menarik dan menyajikan informasiinformasi yang jelas, apakah itu dalam bentuk transaksi, spesifikasi pada produk yang ditawarkan, akan berdampak pada kepercayaan konsumen. Konten situs web memiliki pengaruh positif dan signifikan terhadap trust (Rahimnia dan Hassanzadeh, 2013).

Hasil penelitian (Piarna, 2014) kualitas situs web memiliki pengaruh positif dan signifikan terhadap kepercayaan konsumen dalam transaksi online. Persepsi kepercayaan dipengaruhi secara positif dan signifikan oleh kualitas situs web (Chang et al., 2014). Kualitas situs web memiliki efek positif dan signifikan terhadap kepercayaan pelanggan toko online (Siagian dan Cahyono, 2014). Kualitas situs web memiliki pengaruh positif dan signifikan terhadap kepercayaan konsumen (Shin et al., 2013). Hasil penelitian sejalan dengan penelitian (Purbasari, 2017) dan (Fahmi et al., 2018) yang menyimpulkan bahwa website quality yang semakin baik akan menyebabkan semakin tingginya trust. Beberapa penelitian lain menyimpulkan bahwa Web Quality berpengaruh positif terhadap online trust (Shahnaz dan Wahyono, 2016); (Octavia dan Tamerlane, 2017) dan (Chang et al., 2014).

Berdasarkan hasil perhitungan seperti yang terlihat pada tabel 4 , diperoleh hasil $t$ value sebesar 4,37>1,96, sehingga disimpulkan bahwa variabel Web Quality berpengaruh positif terhadap Repeat Puchase secara signifikan. Dengan demikian, semakin baik Web Quality yang dirasakan responden, maka Repeat Puchase akan semakin baik pula.

Hasil ini memberikan makna bahwa persepsi konsumen yang lebih baik terhadap situs web e-commerce, secara tidak langsung akan mengarah pada niat pembelian kembali konsumen di situs web e-commerce tersebut. Konsumen yang cenderung mendapatkan informasi yang tidak lengkap atau tidak mendapatkan informasi yang baik di situs web e-commerce akan cenderung tidak berbelanja lagi di situs web e-commerce. Kualitas informasi yang tidak lengkap di situs web dan buruknya kualitas interaksi situs web cenderung kurang mendorong niat konsumen untuk membeli kembali niat di situs web. Hal ini karena konsumen cenderung ingin mendapatkan kemudahan dalam menggunakan situs web, penampilan situs web yang menarik dan kelengkapan informasi yang tersedia dalam melakukan transaksi di situs web e-commerce, sehingga walaupun konsumen merasa bahwa kualitas situs baik itu belum tentu mendorong konsumen untuk membeli kembali di situs yang sama, ada kebutuhan untuk kepuasan 
dan kepercayaan yang akan membantu dalam mendorong niat pembelian kembali.

Hal ini didukung oleh penelitian yang dilakukan oleh (Shin et al., 2013) menyatakan bahwa kualitas situs memiliki pengaruh positif dan tidak signifikan terhadap niat pembelian kembali. Hasil penelitian ini juga sejalan dengan penelitian ( $\mathrm{Wu}$ dan Tseng, 2015) yang menyatakan bahwa ketika konsumen merasakan pengalaman berbelanja lebih baik pada transaksi berikutnya, tingkat loyalitas akan meningkat. Demikian juga penelitian yang dilakukan (Puspitasari et al., 2013); (Winnie, 2014) dan (Fahmi et al., 2018) yang menunjukkan bahwa kualitas website berpengaruh terhadap loyalitas pelanggan. Beberapa penelitian lain menyimpulkan bahwa Web Quality berpengaruh positif terhadap Repeat Puchase (Afshardost et al., 2013) dan (Suhardi dan Taufik, 2018).

Berdasarkan hasil perhitungan seperti yang terlihat pada tabel 4 , diperoleh hasil $t$ value sebesar 2,76 $>1,96$, sehingga disimpulkan bahwa variabel Perceived Risk berpengaruh positif terhadap online trust secara signifikan. Dengan demikian, semakin tinggi Perceived Risk yang dirasakan Responden, maka online trust akan semakin baik pula. Menurut (Grabner-Kräuter dan Kaluscha, 2003), mencapai kepercayaan yang lebih kuat dari risiko, sangat penting bagi pemasar online. Hasil penelitian ini sejalan dengan hasil penelitian (Durmus et al., 2017) yang menyatakan bahwa Perceived Risk berpengaruh signifikan terhadap Purchase Intention. Juga didukung oleh penelitian (Bhukya dan Singh, 2015) yang menunjukkan bahwa perceived risk berpengaruh signifikan terhadap intention to purchase. Sedangkan menurut (Chang dan Chen, 2008) perceived risk berpengaruh signifikan terhadap trust. Kepercayaan konsumen akan meningkat karena turunnya tingkat risiko yang dirasakan, semakin rendah tingkat risiko yang dirasakan maka meningkatkan kepercayaan konsumen. Kemudian (Schoorman et al., 2007) dan (Purbasari, 2017) menemukan bahwa perceived risk mempengaruhi trust, perceived risk dipercaya dapat mengurangi kepercayaan konsumen. Beberapa penelitian lain menyimpulkan bahwa Perceived Risk berpengaruh positif terhadap online trust (Putra et al., 2017); (Royani et al., 2018); (Wanda et al., 2018); (Benazić dan Tanković, 2015).

Berdasarkan hasil perhitungan seperti yang terlihat pada tabel 4, diperoleh hasil $t$ value sebesar $2.24>1.96$, sehingga disimpulkan bahwa variabel Perceived Risk berpengaruh positif terhadap Repeat Puchase secara signifikan. Dengan demikian, semakin tinggi Perceived Risk yang dirasakan Responden, maka Repeat Puchase akan semakin baik pula. Ini juga dapat secara sederhana diartikan persepsi akan risiko yang dirasakan konsumen, akan mempengaruhi niat pembelian konsumen. Hasil penelitian menunjukkan bahwa Perceived Risk memiliki pengaruh negatif terhadap purchase intention (Chang dan Chen, 2008) dan (Boyle dan Ruppel, 2006). Hal ini didukung dengan penelitian oleh (Dai et al., 2014) yang meyakinkan mengenai dampak risiko yang dirasakan pada niat pembelian secara online dan perilaku ini dapat dijelaskan oleh kegagalan sebelumnya untuk memperhitungkan efek berisiko dari beberapa kategori produk. Menurut Faqih (2013) perceived risk berpengaruh negatif terhadap purchase intention via online yang berarti konteks lingkungan belanja online melibatkan risiko yang dirasakan tinggi, yang akan mengurangi niat konsumen untuk berbelanja online. Temuan ini relevan dengan penelitian sebelumnya yang dilakukan oleh (Durmus et al., 2017) yang menyatakan bahwa Perceived Risk memiliki dampak signifikan terhadap Purchase Intention. Studi yang dilakukan oleh (Bhukya dan Singh, 2015) juga menunjukkan bahwa risiko yang dirasakan memiliki efek langsung dan signifikan terhadap niat konsumen untuk membeli. Beberapa penelitian lain menyimpulkan bahwa Perceived Risk berpengaruh positif terhadap Repeat Puchase (Wanda et al., 2018); (Benazić dan Tanković, 2015); (Eman et al., 2018) dan (Chiu et al., 2014). 
Berdasarkan hasil perhitungan seperti yang terlihat pada tabel 4 , diperoleh hasil $t$ value sebesar 7,59 > 1,96, maka dapat disimpulkan bahwa variabel Online Trust berpengaruh positif terhadap Repeat Puchase secara signifikan. Dengan demikian, semakin tinggi Online Trust yang dirasakan Responden, maka Repeat Puchase akan semakin baik pula.

Hasil ini memberi arti pada semakin tinggi kepercayaan konsumen pada situs web e-commerce, semakin tinggi niat untuk membeli kembali konsumen di situs web ecommerce. Ini didukung oleh hasil penelitian dari (Trisnawati et al., 2012) menemukan bahwa kepercayaan memiliki efek positif dan signifikan terhadap niat pembelian kembali, jika konsumen merasa bahwa situs web dapat dipercaya, sehingga konsumen mencoba membeli kembali produk di web. Kepercayaan (trust) dinyatakan memiliki efek positif dan signifikan terhadap niat pembelian kembali online (Matute, Polo-Redondo dan Utrillas, 2016).

Kepercayaan adalah faktor penting dalam mempengaruhi perhatian pembelian kembali online (Hsu et al., 2015). Kepercayaan konsumen memiliki efek positif dan signifikan terhadap niat pembelian kembali di situs e-commerce (Norhermaya dan Soesanto, 2016). Penelitian yang dilakukan oleh (Shahnaz dan Wahyono, 2016) yang berkesimpulan bahwa kepercayaan berpengaruh terhadap minat beli konsumen. Dan penelitian lainnya dilakuan oleh (Nurrahmanto dan Rahardja, 2015) yang menyimpulkan bahwa terdapat pengaruh kepercayaan konsumen terhadap minat beli. Beberapa penelitian lain menyimpulkan bahwa Online Trust berpengaruh positif terhadap Repeat Puchase (Putra et al., 2017); (Pujastuti et al., 2015); (Siagian dan Cahyono, 2014); (Octavia dan Tamerlane, 2017) dan (Chang et al., 2014).

Berdasarkan Tabel 5 di atas yang berisi kesimpulan hasil hipotesis model penelitian, dapat disimpulkan bahwa terdapat 2 (dua) pengaruh langsung yang signifikan ber- dasarkan nilai $\mathrm{t}_{\text {hitung }}$ yang lebih besar dari $t_{\text {tabel }} a=5 \%$ (1.96) yaitu. Web Quality berpengaruh terhadap Repeat Puchase melalui variabel Online Trust, dimana merujuk pada tabel dan output nilai thitung nya sebesar 4,56 yang lebih besar dari 1,96, dan bobot pengaruhnya sebesar 0,24 . yang artinya Online Trust dapat memediasi secara positif pengaruh Web Quality terhadap Repeat Puchase dengan bobot sebesar 0,24. Perceived Risk berpengaruh terhadap Repeat Puchase melalui variabel Online Trust, dimana merujuk pada tabel dan output nilai $t_{\text {hitung }}$ sebesar 4,47 yang lebih besar dari 1.96, dan bobot pengaruhnya sebesar 0,24. yang artinya Online Trust dapat memediasi secara positif pengaruh Perceived Risk terhadap Repeat Puchase dengan bobot sebesar 0,24

\section{SIMPULAN DAN SARAN}

Hasil penelitian menunjukkan bahwa Web Quality, Perceived Risk, dan Online Trust berpengaruh signifikan terhadap Repeat Purchase terhadap situs E-Commerce di Kota Medan, begitu juga Web Quality dan Perceived Risk berpengaruh signifikan terhadap online trust terhadap situs ECommerce di Kota Medan. Web Quality berpengaruh terhadap Repeat Puchase melalui variabel Online Trust terhadap situs ECommerce di Kota Medan, dan Perceived Risk berpengaruh terhadap Repeat Purchase terhadap situs E-Commerce di Kota Medan melalui variabel Online Trust.

Peningkatan terhadap privasi konsumen saat melakukan transaksi, yang juga termasuk di dalamnya adanya kontrol keamanan terhadap kerahasiaan data pribadi konsumen saat melakukan transaksi, agar konsumen tidak segan untuk bertransaksi di vendor. Adanya peningkatan dalam pelayanan berupa respon yang lebih cepat terhadap konsumen, baik saat menerima pesanan, pertanyaan ataupun komplain. Sebaiknya pemilik toko online harus mampu mengurangi resiko yang berasal dari transaksi online seperti adanya customer service, jaminan kualitas barang, dan jaminan keamanan dari transaksi tersebut. 
Peneliti selanjutnya diharapkan dapat lebih mengembangkan penelitian ini dengan meneliti faktor lain yang dapat mempengaruhi keputusan pembelian. Penelitian selanjutnya datang diharapkan bisa memperbanyak dan memperluas ukuran sampel penelitian, agar diperoleh gambaran yang lebih baik terhadap minat beli konsumen (purchase intention). Hasil penelitian ini mungkin dapat menjadi masukan dan bahan pertimbangan bagi pemilik toko-toko online di Indonesia, untuk dapat meningkatkan pelayanan dan kualitas toko online sehingga makin terpercaya.

\section{DAFTAR PUSTAKA}

Afshardost, M., S. Farahmandian, dan S. M. S. Eshaghi. 2013. Linking trust, perceived website quality, privacy protection, gender and online purchase intentions. IOSR Journal of Business and Management (IOSR-JBM) 13(4): 63-72.

Aladwani, A. M., dan Palvia, P. C. 2002. Developing and validating an instrument for measuring user-perceived web quality. Information $\mathcal{E}$ Management, 39(2), 467-476. https://doi.org/10. 1016/S0378-7206(01)00113-6

Ali, T. 2016. Factors Deriving Consumers' Repurchase Intention in Online Shopping: a Pakistani Consumer's Perspective. International Journal of Management Sciences and Business Research 5(2): 261-270.

Alkailani, M., dan Kumar, R. 2011. Investigating Uncertainty Avoidance and Perceived Risk for Impacting Internet Buying: A Study in Three National Cultures. International Journal of Business and Management 6(5): 76-92.

Bai, B., Law, R., dan Wen, I. 2008. The impact of website quality on customer satisfaction and purchase intentions: Evidence from Chinese online visitors. International Journal of Hospitality Management 27(3): 391-402. https:/ / doi. org/10.1016/j.ijhm.2007.10.008

Benazić, D., dan Tanković, A. Č. 2015. Impact of Perceived Risk and Perceived Cost on
Trust in the Online Shopping Websites and Customer Repurchase Intention. In 24th CROMAR Congress (104-122).

Bhukya, R., dan Singh, S. 2015. The Effect of Perceived Risk Dimensions on Purchase Intention: An Empirical Evidence from Indian Private Labels Market. American Journal of Business 30(4): 218-230.

Boyle, R. J., dan Ruppel, C. P. 2006. "The Effects Of Personal Innovativeness, Perceived Risk, And Computer SelfEfficacy On Online Purchasing Intent. Journal of International Technology and Information Management 15(2): 61-74.

Chairunnisa, dan Priyono, A. 2018. Interaksi Antara Perceived Value, Transaction Cost, dan Repurchase Intention Dalam Transaksi On-Line. Matrik: Jurnal Manajemen, Strategi Bisnis Dan Kewirausahaan 12(1): 49-60. https://doi.org/ 10.24843/MATRIK:JMBK.2018.v12.i01. p06

Chang, H.-H., dan Chen, S. W. 2008. The impact of online store environment cues on purchase intention: trust and perceived risk as a mediator. Online Information Review 32(6): 818-841. https://doi.org/10.1108/146845208109 23953

Chang, K.-C., Kuo, N.-T., Hsu, C.-L., dan Hsu, C.-L. 2014. The Impact of Website Quality and Perceived Trust on Customer Purchase Intention in the Hotel Sector: Website Brand and Perceived Value as Moderators. International Journal of Innovation, Management and Technology 5(4): 255-260. https://doi.org/10.7763/IJIMT.2014.V 5.523

Chek, Y. L., dan Ho, J. S. Y. 2016. Consumer electronics e-retailing: Why the alliance of vendors' e-service quality, trust and trustworthiness matters. Procedia - Social and Behavioral Sciences, 219: 804-811. https://doi.org/10.1016/j.sbspro.2016. 05.083

Chiu, C., Wang, E. T. G., Fang, Y., dan Huang, H. 2014. Understanding customers' repeat purchase intentions in B2C 
e-commerce: the roles of utilitarian value, hedonic value and perceived risk. Information Systems Journal 24(1): 85-114. https://doi.org/10.1111/j.1365 -2575.2012.00407.x

Chong, B., Yang, Z., dan Wong, M. 2003. Asymmetrical impact of trustworthiness attributes on trust, perceived value and purchase intention: A conceptual framework for cross-cultural study on consumer perception of online auction. In Proceedings of the 5th international conference on electronic commerce Pittsburgh, Pennsylvania (213-219). https://doi.org/10.1145/948005.94803 3

Chou, S.-W., dan Hsu, C.-S. 2015. Understanding online repurchase intention: social exchange theory and shopping habit. Information Systems and E-Business Management, 14(1). https://doi.org/10. 1007/s10257-015-0272-9

Dai, B., Forsythe, S., dan Forsythe, S. 2014. The Impact of Online Shopping Experience on Risk Perceptions and Online Purchase Intentions: Does Product Category Matter? Journal of Electronic Commerce Research 15(1): 1324.

Dai, B., Forsythe, S., dan Kwon, W.-S. 2014. The Impact of Online Shopping Experience on Risk Perceptions and Online Purchase Intentions: Does Product Category Matter? Journal of Electronic Commerce Research 5(1): 13-24.

Doney, P. M., Cannon, J. P., dan Mullen, M. R. 1998. Understanding the Influence of of National Culture on the Development of trust. The Academy of Management Review 23(3): 601-620. https:// doi.org/10.2307/259297

Durmus, B., Ulusu, Y., dan Akgun, S. 2017. The Effect of Perceived Risk on Online Shopping Through Trust and Wom. International Journal of Management and Applied Science 3(9): 103-108.

Eden, D. 1988. Pygmalion, Goal Setting, and Expectancy: Compatible Ways to Raise Productivity. The Academy of Mana- gement Review 13(4): 639-652. https:// doi.org/10.2307/258381

Eman, C., Pangemanan, S., dan Rumokoy, F. S. 2018. Analyzing The Effect of Service Quality and Perceived Risk on Purchase Intention in The Multimart Convenience Store Tomohon City. Jurnal EMBA 6(4): 2477-2487.

Fahmi, M., Prayogi, M. A., dan Jufrizen, J. 2018. Peran kepercayaan pelanggan dalam memediasi pengaruh kualitas website terhadap loyalitas pelanggan online shop. Jurnal Riset Sains Manajemen, 2(3): 121-130. https://doi.org/ 10.5281/zenodo.1477534

Faqih, K. M. S. 2013. Exploring the Influence of Perceived Risk and Internet Selfefficacy on Consumer Online Shopping Intentions: Perspective of Technology Acceptance Model. International Management Review 9(1): 68-78.

Fitdiarini, N. 2015. Kepercayaan Pelanggan untuk Melakukan Online Shopping dan Dampaknya Terhadap Minat Beli Ulang. Jurnal Ekonomi Dan Bisnis 26(3): 256-269.

Ghozali, I. 2008. SEM Metode Alternatif dengan PLS. Badan Penerbit Universitas Diponegoro. Semarang.

Grabner-Kräuter, S., dan Kaluscha, E. A. 2003. Empirical research in on-line trust: a review and critical assessment. International Journal of Human-Computer Studies 58(6): 783-812. https://doi. org/10.1016/S1071-5819(03)00043-0

Gupta, S., dan Kim, H. W. 2007. Developing the Commitment to Virtual Community: The Balanced Effects of Cognition and Affect. Information Resources Management Journal 20(1): 28-45.

Harris, L. C., dan Goode, M. M. H. 2010. Online servicescapes, trust, and purchase intentions. Journal of Services Marketing, 24(3): 230-243. https://doi. org/10.1108/08876041011040631

Heijden, H. van der, Verhagen, T., dan Creemers, M. 2003. Understanding online purchase intentions: Contributions from technology and trust 
perspectives. European Journal of Information Systems 12(1): 41-48.

Hong, I. B. 2015. Understanding the consumer's online merchant selection process: The roles of product involvement, perceived risk, and trust expectation. International Journal of Information Management 35(3): 322-336. https://doi.org/10.1016/j.ijinfomgt.20 15.01 .003

Hsu, M.-H., Chang, C.-M., dan Chuang, L.W. 2015. Understanding the determinants of online repeat purchase intention and moderating role of habit: The case of online group-buying in Taiwan. International Journal of Information Management 35(1): 45-56. https://doi.org/10.1016/j.ijinfomgt.20 14.09.002

Jones, K., dan Leonard, L. N. K. 2008. Trust in consumer-to-consumer electronic commerce. Information $\mathcal{E}$ Management, 45(2): 88-95. https://doi.org/10.1016/ j.im.2007.12.002

Jones, T. O., dan Sasser, W. E. 1995. Why satisfied customers defect. Harvard Business Review 12(6): 11.

Kim, D. J., Ferrin, D. L., dan Rao, H. R. 2008. A trust-based consumer decisionmaking model in electronic commerce: The role of trust, perceived risk, and their antecedents. Decision Support Systems 44(2): 544-564. https://doi. org/10.1016/j.dss.2007.07.001

Kim, H. W., Chan, H. C., dan Gupta, S. 2007. Value-based Adoption of Mobile Internet. Decision Support Systems 43(1): 116-126. https://doi.org/10.1016/j.dss. 2005.05.009

Kim, J., dan Lennon, S. J. 2013. Effects Of Reputation and Website Quality on Online Consumers' Emotion, Perceived Risk and Purchase Intention. Journal of Research in Interactive Marketing 7(1): 3356. https://doi.org/10.1108/17505931 311316734

Kovacs, M., Farias, S. A. de, Moura, F. T., dan Souza, A. G. de. 2011. Relations between consumer effort, risk reduction stra- tegies, and satisfaction with the ecommerce buying process: the development of a conceptual framework. International Journal of Management 28(1): 316-395.

Kuo, Y.-F., Hu, T.-L., dan Yang, S.-C. 2013. Effects of inertia and satisfaction in female online shoppers on repeatpurchase intention: The moderating roles of word-of-mouth and alternative attraction. Journal of Service Theory and Practice 23(3): 168-187. https://doi. org/10.1108/09604521311312219

Li, F., Zhou, N., Kashyap, R., dan Yang, Z. 2008. Brand trust as a second-order factor An alternative measurement model. International Journal of Market Research, 50(6): 1-23. https://doi.org/ 10.2501/S147078530820

Lien, C. H., Wen, M. J., Huang, L. C., dan Wu, K. L. 2015. Online hotel booking: The effects of brand image, price, trust and value on purchase intentions. Asia Pacific Management Review, 20(4), 210218. https://doi.org/10.1016/j.apmrv. 2015.03.005

Lin, H. C. 2008. The Study of the Antecedents of Customer Loyalty on Internet Banking in Indonesia. (Master thesis). UFC, Indonesia.

Lin, J. C., dan Liang, H. 2011. The influence of service environments on customer emotion and service outcomes. Managing Service Quality: An International Journal 21(4): 350-372. https://doi. org/10.1108/09604521111146243

Liu, C., dan Arnett, K. P. 2000. Exploring the Factors Associated with Web Site Success in the Context of Electronic Commerce. Information \& Management, 38(1): 23-33. https://doi.org/10.1016/ S0378-7206(00)00049-5

Lobb, A. E., Mazzocchi, M., dan Traill, W. B. 2007. Modelling risk perception and trust in food safety information within the theory of planned behaviour. Food Quality and Preference 18(2): 384-395. https://doi.org/10.1016/j.foodqual.20 06.04 .004 
Loiacono, E., Watson, R. T., dan Goodhue, D. L. 2002. WEBQUAL: a measure of website quality. In 2002 Marketing Educator's Conference: Marketing Theory and Applications 13: 432-437.

Mahatma, R. 2016. Data Statistik Mengenai Pertumbuhan Pangsa Pasar E-Commerce di Indonesia Saat Ini. Retrieved from https://buattokoonline.id/data-statistik-mengenai-pertumbuhan-pangsapasar-e-commerce-di-indonesia-saatini/

Matute, J., Polo-Redondo, Y., dan Utrillas, A. 2016. The influence of EWOM characteristics on online repurchase intention: Mediating roles of trust and perceived usefulness. Online Information Review, 40(7): 1090-1110. https://doi. org/10.1108/OIR-11-2015-0373

McKnight, D. H., Choudhury, V., dan Kacmar, C. 2002. The Impact of Initial Consumer Trust on Intentions to Transact with a Web Site: A Trust Building Model. The Journal of Strategic Information Systems 11(3-4): 297-323. https://doi.org/10.1016/S09638687(02)00020-3

McOmish, M. A., dan Quester, P. 2005. erceived risk and servicescape: The importance of managing the physical evidence in services marketing. In SERVSIG Research Conference 2005 (55).

Moorman, C., Deshpande, R., dan Zaltman, G. 1993. Factors Affecting Trust in Market Research Relationships. Journal of Marketing, 57(1): 81-101. https:/ / doi. org/10.2307/1252059

Nasution, M. I., Fahmi, M., Jufrizen, J., Muslih, M., dan Prayogi, M. A. 2020. The Quality of Small and Medium Enterprises Performance Using the Structural Equation Model-Part Least Square (SEM-PLS). Journal of Physics: Conference Series, 1477(2020): 1-7. https://doi.org/10.1088/17426596/1477/5/052052

Ndubisi, N. O., dan Moi, C. T. 2005. Customers behaviourial responses to sales promotion: the role of fear of losing face. Asia Pacific Journal of Marketing and Logistics, 17(1): 32-49. https://doi.org/10.1108/135558505106 72278

Nilashi, M., Jannach, D., Ibrahim, O. Bin, Esfahani, M. D., dan Ahmadi, H. 2016. Recommendation quality, transparency, and website quality for trustbuilding in recommendation agents. Electronic Commerce Research and Applications, 19: 70-84. https://doi.org/ 10.1016/j.elerap.2016.09.003

Norhermaya, Y. A., dan Soesanto, H. 2016. Analisis Pengaruh Kepuasan Pelanggan Terhadap Kepercayaan Dan Loyalitas Pelanggan Untuk Meningkatkan Minat Beli Ulang (Studi Pada Online Store Lazada.co.id). Diponegoro Journal of Management 5(3): 1105-1117.

Nurrahmanto, P. A., dan Rahardja, R. 2015. Pengaruh Kemudahan Penggunaan, Kenikmatan Berbelanja, Pengalaman Berbelanja dan Kepercayaan Konsumen Terhadap Minat Beli Konsumen di Situs Beli Online Bukalapak.com. Diponegoro Journal of Management 4(2): 1-12.

O'Cass, A., dan Fenech, T. 2003. Web retailing adoption: Exploring the nature of internet users web retailing behavior. Journal of Retailing and Consumer Services 10(2): 81-94. https://doi.org/10.1016/ S0969-6989(02)00004-8

Octavia, D., dan Tamerlane, A. 2017. The Influence of Website Quality on Online Purchase Intentions on Agoda.Com with E-Trust as a Mediator. Binus Business Review 8(1): 9-14. https://doi. org/10.21512/bbr.v8i1.1680

Pavlou, P. A. 2003. Consumer Acceptance of Electronic Commerce: Integrating Trust and Risk with the Technology Acceptance Mode. International Journal of Electronic Commerce 7(3): 101-134.

Pavlou, P. A., Liang, H., dan Xue, Y. 2007. Understanding and Mitigating Uncertainty in Online Exchange Relationships: A Principal-Agent Perspective. MIS Quarterly 31(1): 105-136. https:// doi.org/10.2307/25148783 
Pavlou, P., dan Gefen, D. 2004. Building Effective Online Marketplaces with Institution-Based Trust. ICIS 2002 Proceedings., 15(1): 37-59. https://doi. org/10.1287/isre.1040.0015

Piarna, R. 2014. Pengaruh Sumber Informasi dan Kualitas Website terhadap Kepercayaan Pelanggan dalam Menentukan Keputusan Bertransaksi pada Ecommerce (Studi pada Pelanggan Ecommerce di Indonesia). Jurnal Aplikasi Manajemen 12(1): 10-21.

Pujastuti, E., Winarno, W. W., dan Sudarmawan. 2015. Pengaruh E-Commerce Toko Online Fashion Terhadap Kepercayaan Konsumen. Citec Journal, 1(2): 139-153.

Purbasari, W. 2017. Model Kepercayaan Konsumen pada Situs E-Commerce. Teknikom 1(1): 39-44.

Puspitasari, A. N., Kumadji, S., dan Sunarti, D. 2013. Pengaruh Kualitas Website Terhadap Nilai yang dipersepsikan, Kepuasan dan Loyalitas Pelanggan Pada Online Shop. Jurnal Administrasi Bisnis 5(2): 1-9.

Putra, I. M. E. W., Dantes, G. R., dan Candiasa, I. M. 2017. Model Pengukuran Tingkat Kepercayaan Pelanggan (Online Trust) Terhadap Situs ECommerce (Studi Kasus Pada Pelanggan E-Commerce di Provinsi Bali). Journal of Natural Science and Engineering 1(3): 100-109.

Rahimnia, F., dan Hassanzadeh, J. F. 2013. The impact of website content dimension and e-trust on e-marketing effectiveness: The case of Iranian commercial saffron corporations. Information \& Management 50(5): 240247. https://doi.org/10.1016/j.im.2013. 04.003

Royani, F., Kusyanti, A., dan Aryadita, H. 2018. Analisis Keterkaitan Tingkat Kepercayaan Pengguna Dalam Melakukan Transaksi Online (E-Commerce) Pada Instagram. Jurnal Pengembangan Teknologi Informasi Dan Ilmu Komputer 2(9): 2735-2741.

Salo, J., dan Karjaluoto, H. 2007. A conceptual model of trust in the online environment. Online Information Review, 31(5), 604-621. https://doi.org/10. 1108/14684520710832324

Samadi, M., dan Yaghoob-Nejadi, A. 2009. A Survey of the Effect of Consumers' Perceived Risk on Purchase Intention in E-Shopping. Business Intelligence Journal 2(2): 261-275.

Schiffman, L. G., dan Wisenblit, J. L. 2015. Consumer Behavior (11th ed.). Harlow, United Kingdom: Pearson Education Limited.

Schoorman, F. D., Mayer, R. C., dan Davis, J. H. 2007. An Integrative Model of Organizational Trust: Past, Present, and Future. Academy of Management Review 32(2): 344-354.

Shahnaz, N. B. F., dan Wahyono. 2016. Faktor Yang Mempengaruhi Minat Beli Konsumen Di Toko Online. Management Analysis Journal 5(4): 389-399. https:// doi.org/10.15294/MAJ.V5I4.5571

Sharma, V. M. 2013. Enhancement of trust in the export management companysupplier relationship through ebusiness. International Journal of Commerce and Management 23(1): 24-37. https://doi.org/10.1108/105692113113 11131

Shin, J. I., Chung, K. H., Oh, J. S., dan Lee, C. W. 2013. The effect of site quality on repurchase intention in Internet shopping through mediating variables: The case of university students in South Korea. International Journal of Information Management 33(3): 453-463. https:/ / doi.org/10.1016/j.ijinfomgt.20 13.02.003

Siagian, H., dan Cahyono, E. 2014. Analisis Website Quality, Trust dan Loyalty Pelanggan Online Shop. Jurnal Manajemen Pemasaran 8(2): 55-61. https:// doi.org/10.9744/pemasaran.8.2.55-61

Sin, S. S., Nor, K. M., dan Al-Agaga, A. M. 2012. Factors Affecting Malaysian young consumers' online purchase intention in social media websites. Procedia-Social and Behavioral Sciences, 
40, 326-333. https://doi.org/10.1016/ j.sbspro.2012.03.195

Suhardi, D., dan Taufik, N. 2018. The Analysis of Ease of Use, Trust and Website Quality towards Purchasing Decision in Lazada.co.id. Indonesian Journal of Business and Economics 1(1): $38-48$.

Trisnawati, E., Suroso, A., dan Kumorohadi, U. (2012). Analisis Faktor faktor Kunci dari Niat Pembelian Kembali secara Online (Studi Kasus pada Konsumen Fesh Shop). Jurnal Bisnis Dan Ekonomi (JBE) 19(2): 126-141.

Umar, H. 2000. Riset Pemasaran Dan Penilaian Konsumen. PT Gramedia Pustaka Utama. Jakarta.

Wanda, D. Y. C., Kusumawati, A., dan Sanawiri, B. 2018. The Influence of Perceived Risk Toward Trust and Its Impact on Purchase Intention (Study on Go-Ride Consumer in Malang City). Jurnal Administrasi Bisnis 64(1): 145-152.

Wang, L., Law, R., Guillet, B. D., Hung, K., dan Fong, D. K. C. 2015. Impact of hotel website quality on online booking intentions: eTrust as a mediator. International Journal of Hospitality Management 47: 108-115. https://doi. org/10.1016/j.ijhm.2015.03.012

Weisberg, J., Te'eni, D., dan Arman, L. 2011. Past purchase and intention to purchase in e-commerce. Internet Research 21(1): 82-96. https://doi.org/10.1108/106622 41111104893

Winnie, P.-M. W. 2014. The Effects of Website Quality on Customer eLoyalty: The Mediating Effect of Trustworthiness. International Journal of Academic Research in Business and Social Sciences 4(3): 19-41.
Wolfinbarger, M., dan Gilly, M. C. 2003. etailQ: dimensionalizing, measuring and predicting etail quality. Journal of Retailing 79(3): 183-198. https://doi. org/10.1016/S0022-4359(03)00034-4

Wu, M.-Y., dan Tseng, L.-H. 2015. Customer Satisfaction and Loyalty In An Online Shop: An Experiential Marketing Perspective. International Journal of Business and Management 10(1): 104-114. https:/ / doi.org/10.5539/ijbm.v10n1p104

Yoo, B., dan Donthu, N. 2001. Developing a scale to measure the perceived quality of an Internet shopping site (SITEQUAL). Quarterly Journal of Electronic Commerce 2(1): 31-47.

Youl, H. H., dan Swinder, J. 2014. The effect of customized information on online purchase intentions. Internet Research, 24(4): 496-519. https://doi.org/10. 1108/IntR-06-2013-0107

Yousafzai, S. Y., Pallister, J. G., dan Foxall, G. R. 2003. A proposed model of e-trust for electronic banking. Technovation 23(11): 847-860. https://doi.org/10.1016/S01 66-4972(03)00130-5

Zeithaml, V. A., Parasuraman, A., dan Malhotra, A. 2002. Service Quality Delivery Through Web Sites: A Critical Review of Extant Knowledge. Journal of the Academy of Marketing Science 30(4): 358-371. https://doi.org/10.1177/0092 07002236911

Zheng, L., Favier, M., Huang, P., dan Coat, F. 2012. Chinese consumer perceived risk and risk relievers in e-shopping for clothing. Journal of Electronic Commerce Research 13(3): 255-274. 